\title{
Removal of Se(IV) and Se(VI) from drinking water by coagulation
}

\author{
Chengzhi Hu, Qingxin Chen, Guixia Chen, Huijuan Liu*, Jiuhui Qu \\ Key Laboratory of Drinking Water Science and Technology, Research Center for Eco-Environmental Sciences, Chinese Academy of Sciences, Beijing 100085, China
}

\section{A R T I C L E I N F O}

\section{Article history:}

Received 13 October 2014

Received in revised form 25 December 2014

Accepted 26 December 2014

Available online 3 January 2015

\section{Keywords:}

Selenium

Coagulation

Drinking water

Al based coagulant

Ferric chloride

\begin{abstract}
A B S T R A C T
Selenium (Se) is one of contaminants required to be regulated during drinking water treatment, however, little information has been collected to date regarding Se removal by coagulation. In this study, the performance of Se removal by coagulation has been evaluated with respect to the dependence on Se species, coagulant type, water $\mathrm{pH}$ and interfering ions. The results showed that a Fe-based coagulant was much more efficient than Al-based coagulants in Se removal. The removal of selenite (Se(IV)) by coagulation was much more pronounced than that of selenate $(\mathrm{Se}(\mathrm{VI})$ ). With an FC dosage of more than $0.4 \mathrm{mM} \mathrm{Fe} / \mathrm{L}, \mathrm{Se}(\mathrm{IV})$ removal efficiency of more than $98 \%$ could be achieved when the initial Se(IV) concentration was $250 \mu \mathrm{g} / \mathrm{L}$. For Al-based coagulants $\left(\mathrm{AlCl}_{3}(\mathrm{AC})\right.$ and polyaluminum chloride (PACl) $\mathrm{Se}$ removal efficiency was positively correlated with the content of $\mathrm{Al}_{13}$ species during the coagulation process. Adsorption onto hydroxide flocs was the most active coagulation mechanism for Se removal and precipitation also played specific roles at low dosage, especially for Se(IV) removal and with Fe coagulant. High coagulant dosage and weakly acidic $\mathrm{pH}$ could enhance the formation of hydroxide flocs having more active adsorption sites and high zeta potential, and thus favored Se removal. These findings are important to understand the efficiency and mechanisms of Se removal by coagulation.
\end{abstract}

(c) 2015 Elsevier B.V. All rights reserved.

\section{Introduction}

Selenium (Se) is an essential trace element for both animals and humans, but it can be toxic if taken in excess [1]. Excessive amounts of Se can cause lower reproduction rate and fetal deformity $[2,3]$. Its toxicity led the World Health Organization (WHO) to recommend a maximum Se concentration in drinking water of $10 \mu \mathrm{g} / \mathrm{L}$. Se is introduced in the environment from both natural and anthropogenic sources. Agriculture and combustion of fossil fuels are the primary sources of Se from human activities [4]. It is reported that the surface and ground water in some areas of China, India and America contain much higher levels of Se (45$341 \mu \mathrm{g} / \mathrm{L}$ ) than required by the drinking water standard [4-6]. In the environment, Se can exist in different oxidation states: elemental selenium $\left(\mathrm{Se}^{0}\right)$, selenite $\left(\mathrm{SeO}_{3}^{2-}, \mathrm{Se}(\mathrm{IV})\right)$, selenide $\left(\mathrm{Se}^{2-}\right)$, selenate $\left(\mathrm{SeO}_{4}^{2-}, \mathrm{Se}(\mathrm{VI})\right)$ and organic Se [7]. Se(IV) and $\mathrm{Se}(\mathrm{VI})$ are found in most aqueous media and are the predominant chemical forms [1]. The toxicity of Se depends on its oxidation state. Se(IV) is considered to be more toxic than $\mathrm{Se}(\mathrm{VI})$ [8].

A variety of treatment methods have been studied for Se removal from contaminated waters, including ion-exchange [9], reverse osmosis [10], zero-valent iron [11], microbial reduction

\footnotetext{
* Corresponding author. Tel.: +86 10 62849128; fax: +86 1062849160 .

E-mail address: hjliu@rcees.ac.cn (H. Liu).
}

[12], chemical precipitation [13], a hybrid electro-coagulation membrane process [14] and adsorption [15-23]. Among these, adsorption is believed to be the most promising process and has been studied extensively. Metal oxides such as various iron ( $\mathrm{Fe}$ ) oxides and aluminum (Al) oxide have been demonstrated to be effective adsorbents for Se removal [15,18,20,22-24]. Coagulation by $\mathrm{Al}$ and $\mathrm{Fe}$ salts is an important water treatment process and has been widely used in drinking water plants. For Al salt that is the most commonly used coagulant, it has been believed that the $\mathrm{Al}$ species distribution during coagulation can determine the coagulation behavior and efficiency $[25,26]$. After coagulant addition, Al or Fe cations hydrolyze quickly and in-situ form abundant precipitates of $\mathrm{Al}$ or Fe hydroxide oxides. Contaminant adsorption to $\mathrm{Al}$ or Fe hydroxide oxide can play a very important role in the coagulation process $[27,28]$. Therefore, coagulation may be an effective technology to remove Se through adsorption by Al or Fe hydroxide oxide. Coagulation is an existing water treatment process in drinking water plants. However, so far no study has been conducted on the removal of Se from drinking water by coagulation.

The objective of this paper is to evaluate the coagulation performance in Se removal. The efficiency of Se(IV) and Se(VI) removal by $\mathrm{Al}$ and $\mathrm{Fe}$ salts as coagulants was examined using jar tests. The effect of water $\mathrm{pH}$ and coexisting anions on Se removal by coagulation was clarified. The effect of Al speciation on Se removal was also investigated from the viewpoint of $\mathrm{Al}$ species transformation. 
The present study also provided insight into the mechanisms of Se removal by $\mathrm{Al}$ - and Fe-based coagulants. We hope this work contributes to effective Se removal during coagulation process and makes drinking water supply more safely.

\section{Materials and methods}

\subsection{Materials}

All of the chemical solutions used in this study were prepared using de-ionized water and analytical grade chemicals. $\mathrm{FeCl}_{3}(\mathrm{FC})$ was used as the Fe-based coagulant. $\mathrm{AlCl}_{3}(\mathrm{AC})$ and polyaluminum chloride $(\mathrm{PACl})$ were used as a traditional Al-based coagulant and inorganic Al polymer flocculant, respectively. $\mathrm{PACl}$ was prepared by an electrochemical process [29]. The predominant $\mathrm{Al}$ species of $\mathrm{AC}$ and $\mathrm{PACl}$ were $\mathrm{Al}$ monomer $\left(\mathrm{Al}_{\mathrm{m}}\right)$ and $\mathrm{Al}_{13}$ polymer, respectively. $\mathrm{Al}_{13}$ polymer in $\mathrm{PACl}$ used in this study accounted for $87.1 \%$ of the total Al concentration, which was analyzed using the method of ${ }^{27} \mathrm{Al}$ nuclear magnetic resonance [30]. $1000 \mathrm{mg} / \mathrm{L}$ $\mathrm{Se}(\mathrm{IV})$ and $\mathrm{Se}(\mathrm{VI})$ stock solutions were prepared by dissolving $\mathrm{Na}_{2} \mathrm{SeO}_{3}$ and $\mathrm{Na}_{2} \mathrm{SeO}_{4} \cdot 10 \mathrm{H}_{2} \mathrm{O}$ (both from Aldrich) into de-ionized water, respectively. Water samples were synthesized by spiking $\mathrm{Se}(\mathrm{IV})$ or $\mathrm{Se}(\mathrm{VI})$ into tap water for coagulation and adsorption experiments. The initial Se concentration was $250 \mu \mathrm{g} / \mathrm{L}$ for all experiments.

\subsection{Determination of Se concentration}

Se concentration was analyzed by a spectrometer (AF-610, Beijing Rull Analytical Instrument Co., Ltd., China) on the basis of hydride generation-atomic fluorescence spectrometry [31]. The operation conditions were as follows: PMT-voltage of $220 \mathrm{mV}$, lamp current of $50 \mathrm{~mA}$, argon carrier gas flow rate of $800 \mathrm{~mL} /$ min, and atomization at room temperature. All samples used in our analysis were analyzed within $24 \mathrm{~h}$ of collection. Total Se ( $\mathrm{Se}(\mathrm{IV})$ and $\mathrm{Se}(\mathrm{VI})$ ) concentration analysis was performed as follows: $10 \mathrm{~mL}$ of filtered supernatant was transferred into a $15 \mathrm{~mL}$ test tube, then $1.5 \mathrm{~mL} \mathrm{HCl}(6 \mathrm{~mol} / \mathrm{L})$ was added. The solution was heated to $90{ }^{\circ} \mathrm{C}$ for $30 \mathrm{~min}$, then was diluted to $15 \mathrm{ml}$ with $1.2 \mathrm{~mol} / \mathrm{L} \mathrm{HCl}$ for final analysis. $\mathrm{HCl}(1.2 \mathrm{~mol} / \mathrm{L})$ and potassium borohydride ( $15 \mathrm{~g} / \mathrm{L}$, containing $2 \mathrm{~g} / \mathrm{L} \mathrm{NaOH}$ ) were used as carrying fluid.

\subsection{Jar test}

Jar tests were performed using a six-paddle stirrer. The procedures consisted of a 2 min rapid mix (200 rpm), 30 min slow mix $(40 \mathrm{rpm})$, and a $30 \mathrm{~min}$ settling period, after which the supernatants were sampled and filtered by a $0.45 \mu \mathrm{m}$ pore size membrane filter. The filtrates were tested for Se concentration. A small amount of sample was taken immediately to measure Zeta potential (Zetasizer 2000, Malvern, UK) during the slow mix period. Before the coagulant dose a predetermined amount of $0.2 \mathrm{~mol} / \mathrm{L}$ $\mathrm{NaOH}$ or $0.05 \mathrm{~mol} / \mathrm{L} \mathrm{HCl}$ solution was added into water samples to approximately get an expected $\mathrm{pH}$ value. After dosing with coagulants, water $\mathrm{pH}$ was accurately adjusted to the expected value during the rapid mix period by adding $\mathrm{HCl}$ or $\mathrm{NaOH}$ solution, after which the water $\mathrm{pH}$ was constant during the subsequent flocculation process.

\subsection{Adsorption experiments}

Adsorption experiments were initiated to evaluate Se(IV) and $\mathrm{Se}(\mathrm{VI})$ removal by adsorption on $\mathrm{Al}$ or Fe hydroxide flocs. In the water samples without Se, hydroxide flocs preformed during the slow mix periods. After this, a certain amount of Se was added into the preformed floc suspension and then the slow mixing (40 rpm) was maintained for $30 \mathrm{~min}$ to allow the Se to be adsorbed. After the adsorption step, the settling step was applied. The experimental conditions for adsorption were same as those for coagulation. The Se removal performance by adsorption was compared with that by coagulation.

\subsection{Effect of competing anions on Se removal}

To test the effects of co-existing anions on Se(IV) removal by coagulation, four types of oxyanions $\left(\mathrm{SO}_{4}^{2-}, \mathrm{CO}_{3}^{2-}, \mathrm{SiO}_{3}^{2-}\right.$ and $\mathrm{PO}_{4}^{3-}$ ) of similar molecular structures were evaluated individually. The experiments were conducted at $\mathrm{pH}$ 6.0. To avoid the interference of matrix constituents in tap water, the experiments were carried out with de-ionized water containing $0.5 \mathrm{mmol} / \mathrm{L} \mathrm{NaNO}_{3}$. Water samples were synthesized by spiking co-existing anions into de-ionized water for the experiments of co-existing anions effect. The concentrations of the four oxyanions were controlled at three levels $(0.1,1$ and $10 \mathrm{mM})$.

\section{Results and discussion}

\subsection{Se removal by $\mathrm{Al}$ - and Fe-based coagulants}

Fig. 1 shows the results of Se(IV) and Se(VI) removal by FC, AC and PACl. With the increase of coagulant dosage, Se(IV) and Se(VI) concentration gradually decreased, except at the high dosages of AC. FC was more effective for Se removal than the Al-based coagulants. The removal efficiency of Se(IV) by FC could reach above $98 \%$ at dosages of more than $0.4 \mathrm{mmol} \mathrm{Fe} / \mathrm{L}$, while the maximum removal efficiency of Al-based coagulants was about $80 \%$ at the dosage of $1.2 \mathrm{mmol} \mathrm{Al} / \mathrm{L}$. The removal efficiency of $\mathrm{Se}(\mathrm{VI})$ by $\mathrm{FC}$ was also notably higher than that by the two Al salts at the same coagulant dosages. Fig. 1 shows that the removal of Se(IV) by coagulation was much more effective than that of $\mathrm{Se}(\mathrm{VI})$. For example, at the dosage of $0.4 \mathrm{mmol} / \mathrm{L} \mathrm{Fe}$ or $\mathrm{Al}$, the removal efficiencies of $\mathrm{Se}(\mathrm{IV})$ were twice as high as those of $\mathrm{Se}(\mathrm{VI})$. Se(IV) concentrations

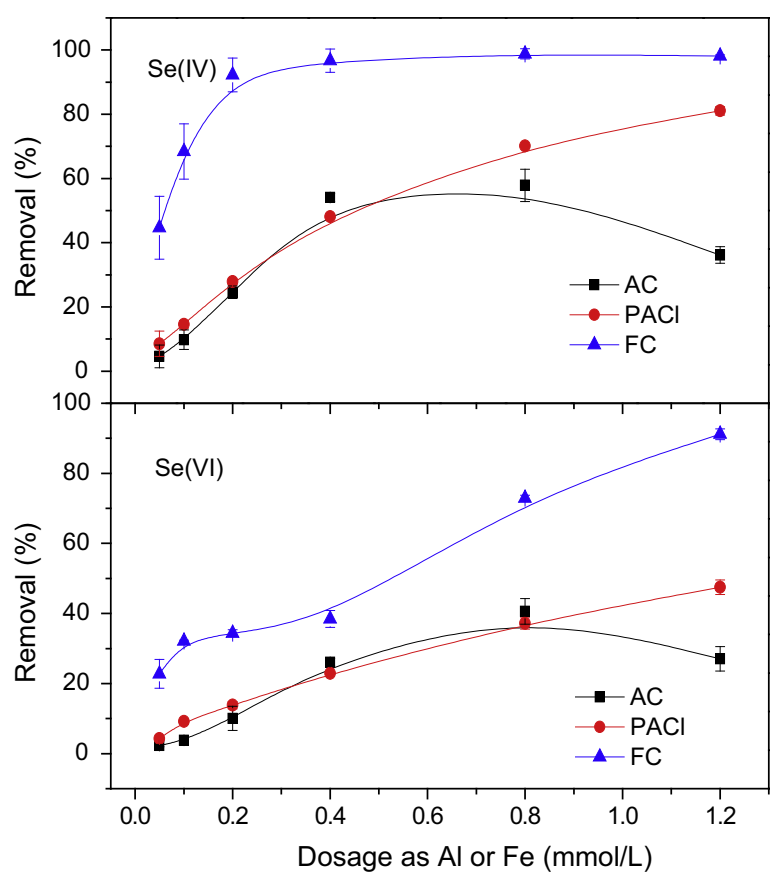

Fig. 1. The removal of Se as a function of coagulant dose. Initial water pH was 7.67 
in the product water after treatment by more than $0.4 \mathrm{mmol} \mathrm{Fe} / \mathrm{L}$ FC could meet the required maximum contaminant level (10 $\mu \mathrm{g} \mathrm{Se/L)}$.

Both $\mathrm{AC}$ and $\mathrm{PACl}$ could remove some Se, but the coagulation behaviors of $A C$ and PACl were different. Fig. 1 shows that the performance of $\mathrm{PACl}$ in Se removal was more stable than that of $\mathrm{AC}$. The Se removal efficiency of $A C$ at the middle dosage $(0.4 \mathrm{mmol} / \mathrm{L})$ was higher than that of $\mathrm{PACl}$, while lower at the low $(0.05-0.2 \mathrm{mmol} / \mathrm{L})$ and high (more than $0.8 \mathrm{mmol} / \mathrm{L}$ ) dosages. Fig. 2 shows that water $\mathrm{pH}$ was depressed by coagulant addition. The most significant decline of water $\mathrm{pH}$ was observed with FC coagulation. For Al-based coagulants, the extent of the drop was inverse to the coagulant basicity. From the lowest dosage to highest dosage, the $\mathrm{pH}$ value with AC addition decreased from 7.5 to 4.2 , which was larger than the $\mathrm{pH}$ range with $\mathrm{PACl}$. At the optimal dosage (about $0.6 \mathrm{mmol} / \mathrm{L}$ ) of $\mathrm{AC}$ for Se removal, the final $\mathrm{pH}$ was weakly acidic (about $\mathrm{pH} 5$ ), which has been proven to be the optimal $\mathrm{pH}$ condition for AC coagulation. It has been demonstrated that water $\mathrm{pH}$ plays an important role in $\mathrm{Al}$ species distribution during the coagulation process $[25,32]$, which may contribute to the differences between AC and $\mathrm{PACl}$ in Se removal. The effect of $\mathrm{pH}$ on Se removal by coagulation was further investigated and discussed in the following text.

\subsection{Effect of $\mathrm{pH}$ on Se removal}

The effect of $\mathrm{pH}$ on Se removal was evaluated in the range of $\mathrm{pH}$ 2-9 for FC and 4-9 for the two Al-based coagulants, respectively. As shown in Figs. 3 and 4, the effect of $\mathrm{pH}$ on Se(IV) removal by coagulation was similar to that on $\mathrm{Se}(\mathrm{VI})$ removal. In the range of $\mathrm{pH}$ 4-9, the $\mathrm{Se}(\mathrm{IV})$ and $\mathrm{Se}(\mathrm{VI})$ removal efficiencies with $0.1 \mathrm{mmol} \mathrm{Fe} / \mathrm{L}$ FC were clearly higher than those using the two Al-based coagulants at $0.4 \mathrm{mmol} \mathrm{Al} / \mathrm{L}$. Compared with Al-based coagulants, the Se removal by FC was less dependent on $\mathrm{pH}$. The optimal pH for Se removal by FC was lower than for the Al-based coagulants. The optimal $\mathrm{pH}$ values for $\mathrm{Se}(\mathrm{IV})$ and $\mathrm{Se}(\mathrm{VI})$ removal by FC, AC and PACl were about 4,5 and 6 , respectively. Figs. 3 and 4 shows that the trend of Se removal as a function of $\mathrm{pH}$ resembled that of the zeta potential, which indicated that Se removal by coagulation positively correlated with the zeta potential of the hydroxide flocs. The optimal $\mathrm{pH}$ for Se removal was approximately consistent with the $\mathrm{pH}$ values for the maximal zeta potential. The result revealed that the surface potential of flocs might play an important role in coagulation to remove Se. The zeta potential of flocs was positive at weakly acidic conditions, where the $\mathrm{Se}(\mathrm{IV})$ and $\mathrm{Se}(\mathrm{VI})$ removal efficiency reached the maximal value. Since both $\mathrm{Se}(\mathrm{IV})$ and $\mathrm{Se}(\mathrm{VI})$ are anions in water, the high

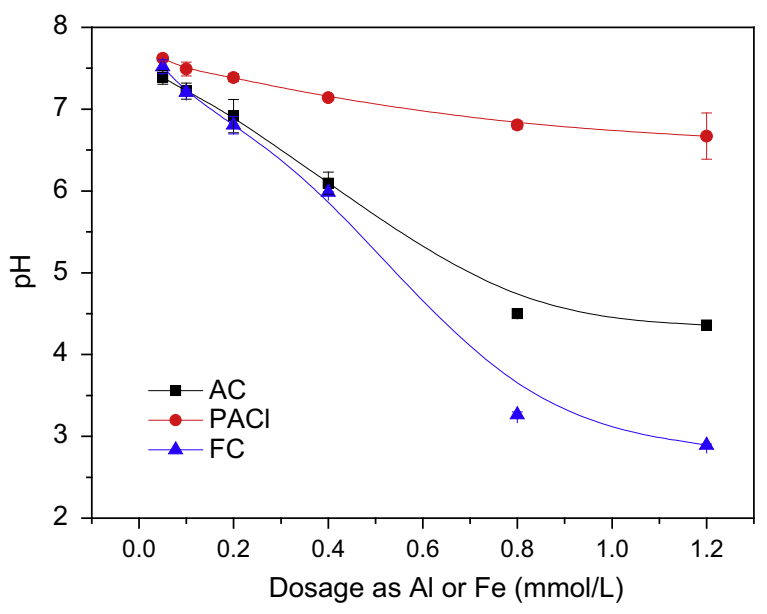

Fig. 2. Finished pH of water samples as a function of coagulant dose.

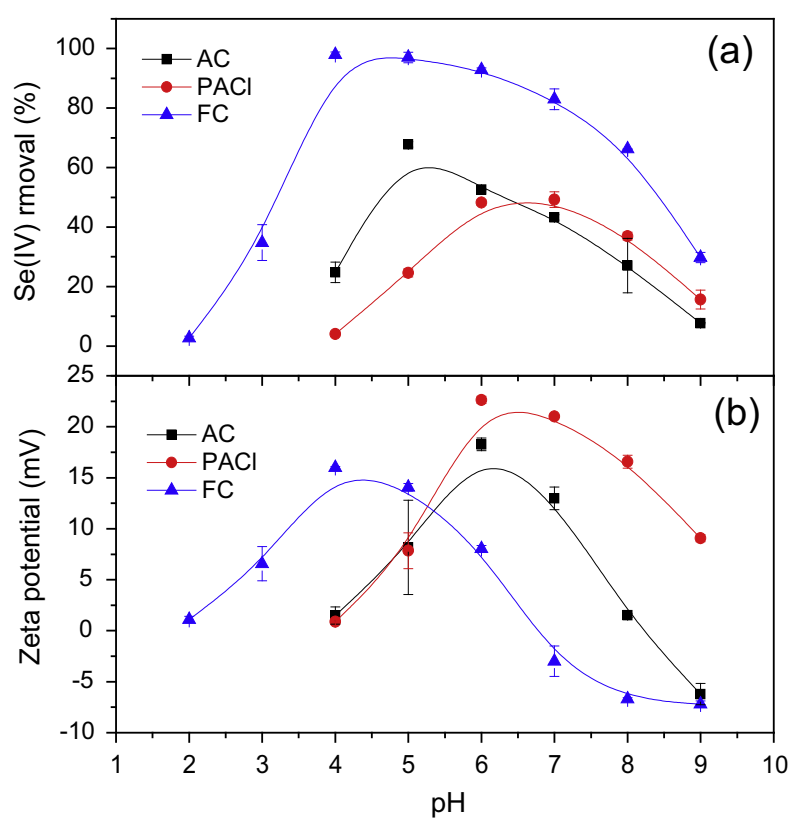

Fig. 3. Effect of pH on Se(IV) removal (a) and zeta potential of hydroxide flocs (b). The dosages of $\mathrm{Al}$ based coagulants and $\mathrm{FC}$ were constant at $0.4 \mathrm{mmol} \mathrm{Al} / \mathrm{L}$ and $0.1 \mathrm{mmol} \mathrm{Fe} / \mathrm{L}$, respectively.

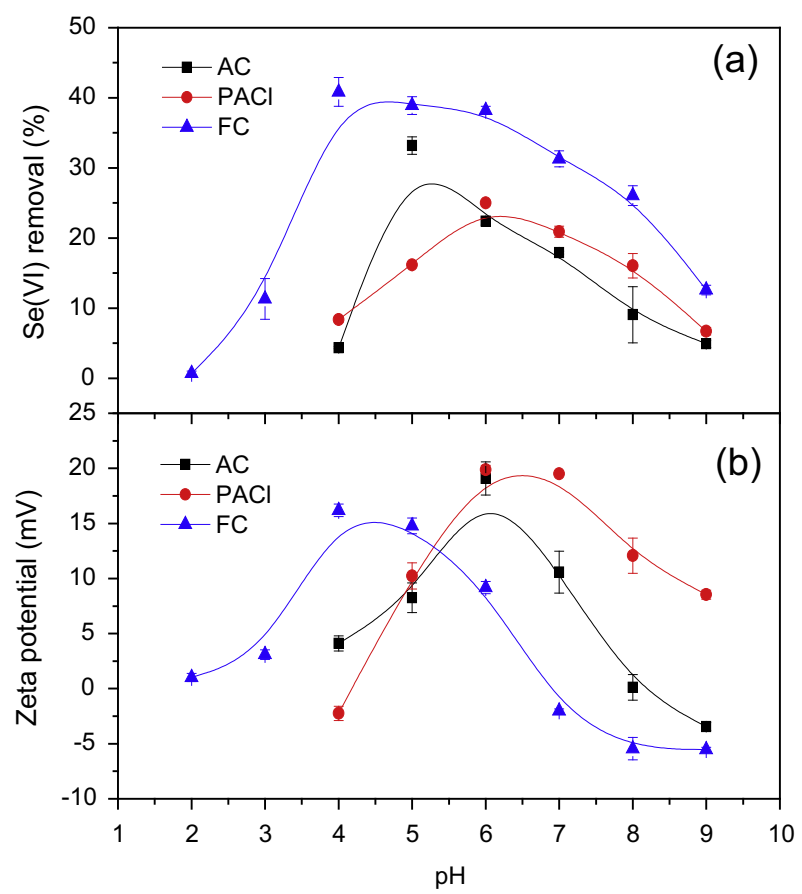

Fig. 4. Effect of $\mathrm{pH}$ on $\mathrm{Se}(\mathrm{VI})$ removal (a) and zeta potential of hydroxide flocs (b). The dosages of $\mathrm{Al}$ based coagulants and $\mathrm{FC}$ were constant at $0.4 \mathrm{mmol} \mathrm{Al} / \mathrm{L}$ and $0.1 \mathrm{mmol} \mathrm{Fe} / \mathrm{L}$, respectively.

positive charge of flocs facilitated the Se removal during the coagulation process. Generally, Fe and Al hydroxide flocs readily and largely form in weakly acidic $\mathrm{pH}$ conditions due to the minimum solubility of $\mathrm{Al}$ and $\mathrm{Fe}$ in water in this $\mathrm{pH}$ region. Abundant hydroxide flocs may favor Se removal through coprecipitation into growing hydroxide and adsorption on formed hydroxide flocs, which are believed to be the main mechanisms for removal of anionic contaminants by the coagulation process. Hydrous Fe oxides are less soluble than hydrous $\mathrm{Al}$ oxides, thus producing more flocs for Se 
coprecipitation and adsorption during the coagulation process [33], which may contribute to the better performance of FC in Se removal.

Figs. 3 and 4 show that both Se(IV) and Se(VI) removals by AC were higher than those by $\mathrm{PACl}$ in the $\mathrm{pH}$ range 5-6.5, which was the optimal $\mathrm{pH}$ range for Se removal by Al-based coagulants. At acidic and alkaline $\mathrm{pH}$ conditions, except $\mathrm{Se}(\mathrm{IV})$ removal at $\mathrm{pH}$ 4 , Se removal by AC was inferior to that by $\mathrm{PACl}$. The optimal $\mathrm{pH}$ value ( $\mathrm{pH}$ ) for Se removal by $\mathrm{AC}$ was lower than that $(\mathrm{pH} 6)$ by $\mathrm{PACl}$. $\mathrm{Al}$ monomer and $\mathrm{Al}_{13}$ polymer were the dominant $\mathrm{Al}$ species for $\mathrm{AC}$ and $\mathrm{PACl}$, respectively. $\mathrm{Al}_{13}$ polymer has been believed to be the most active species in $\mathrm{Al}$ coagulants responsible for coagulation $[25,26,34]$. It has been demonstrated that $\mathrm{Al}_{13}$ polymer could largely form in-situ through the transformation of $\mathrm{Al}$ monomer in a weakly acidic $\mathrm{pH}$ environment, while preformed $\mathrm{Al}_{13}$ polymer was quite stable even in acidic and alkaline $\mathrm{pH}$ conditions [25,32]. Overall, PACl performance in Se removal was less dependent on $\mathrm{pH}$ than AC. This may be a result of the stable character of preformed $\mathrm{Al}_{13}$ polymer during the $\mathrm{PACl}$ coagulation process. By comparison, AC showed a relatively labile performance with $\mathrm{pH}$ change. The higher removal efficiency at middle dosage (Fig. 1) and weakly acidic pH condition (Figs. 3 and 4) may be ascribed to the function of in-situ formed $\mathrm{Al}_{13}$ polymer during the AC coagulation process. This indicated that for Al-based coagulants, Se removal efficiency was positively correlated with the content of $\mathrm{Al}_{13}$ species during the coagulation process.

\subsection{The mechanism of Se removal by coagulation}

Three mechanisms for the removal of anionic contaminants (e.g. P, As and $\mathrm{Sb}$ ) by $\mathrm{Al}$ and Fe-based coagulants have been suggested [35-37]: (i) Precipitation and formation of insoluble compounds; (ii) Coprecipitation into growing hydroxide; (iii) Adsorption onto formed hydroxide flocs. In the present study, special experiments were performed to discriminate between these mechanisms and determine which one is predominant, and the differences between PACl, AC and FC during Se(IV) and Se(VI) coagulation removal. The results of Se coagulation by $\mathrm{AC}$ and $\mathrm{PACl}$ and adsorption by the corresponding hydroxide flocs at $\mathrm{pH} 6$ are shown together in Fig. 5. Similar trends were observed in adsorption and coagulation processes with $\mathrm{AC}$ and $\mathrm{PACl}$. The Se removal efficiency of both coagulation and adsorption increased with the increase of coagulant dose. Although Se removal by coagulation was more efficient than that by hydroxide floc adsorption, the gap in Se removal efficiency between adsorption and coagulation was small. The gap in Se(IV) removal was larger than that of Se(VI). The difference was more pronounced at low dosages than high dosages. Se(IV) removal by adsorption and coagulation both for $\mathrm{AC}$ and $\mathrm{PACl}$ were almost the same at high dosages, where the removal efficiency was close to $100 \%$ (Fig. 5a). Se removal by FC coagulation and FC floc adsorption was investigated at $\mathrm{pH} 6$ and 4, respectively. As shown in Fig. 6, similar trends were also observed in adsorption and coagulation processes with FC. The gap in Se(IV) removal efficiency between FC coagulation and FC floc adsorption, except at the high dosages, was significantly larger than those of Al-based coagulants and that of $\mathrm{Se}(\mathrm{VI})$. In addition, the difference was more pronounced at $\mathrm{pH} 6$ than at $\mathrm{pH}$ 4. The results from these experiments indicated that adsorption onto hydroxide precipitations was the most important mechanism for Se removal by Al and Fe coagulants and precipitation/coprecipitation also played specific roles at low dosage, especially for $\mathrm{Se}(\mathrm{IV})$ removal and with Fe coagulant. Adsorption onto hydroxide flocs played a more important role in Se(IV) removal, and it was almost the sole coagulation mechanism when $\mathrm{Se}(\mathrm{IV})$ removal efficiency reached more than 95\%. Previous studies $[36,38,39]$ obtained similar results when they studied the coagulation behavior of Al- or Fe-based coagulants in the removal
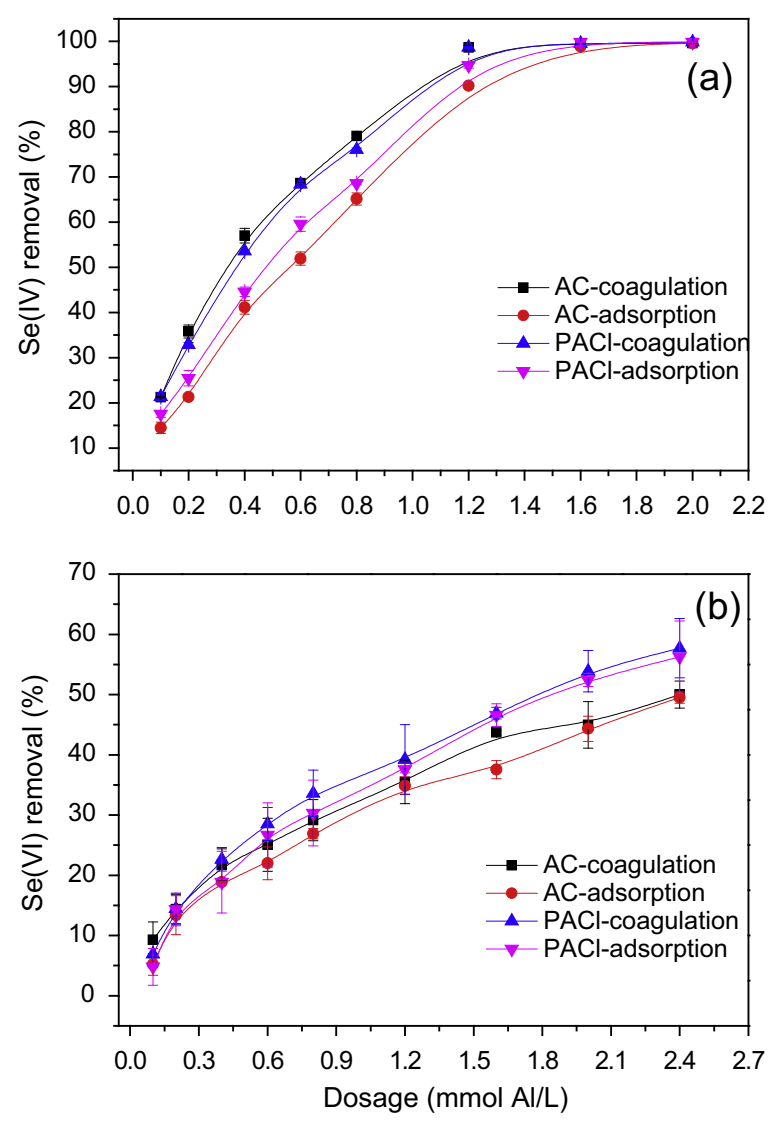

Fig. 5. Se removal by $\mathrm{AC}$ and $\mathrm{PACl}$ coagulation and adsorption on preformed $\mathrm{AC}$ and $\mathrm{PACl}$ hydroxide flocs. Water $\mathrm{pH}$ was constant at 6 .
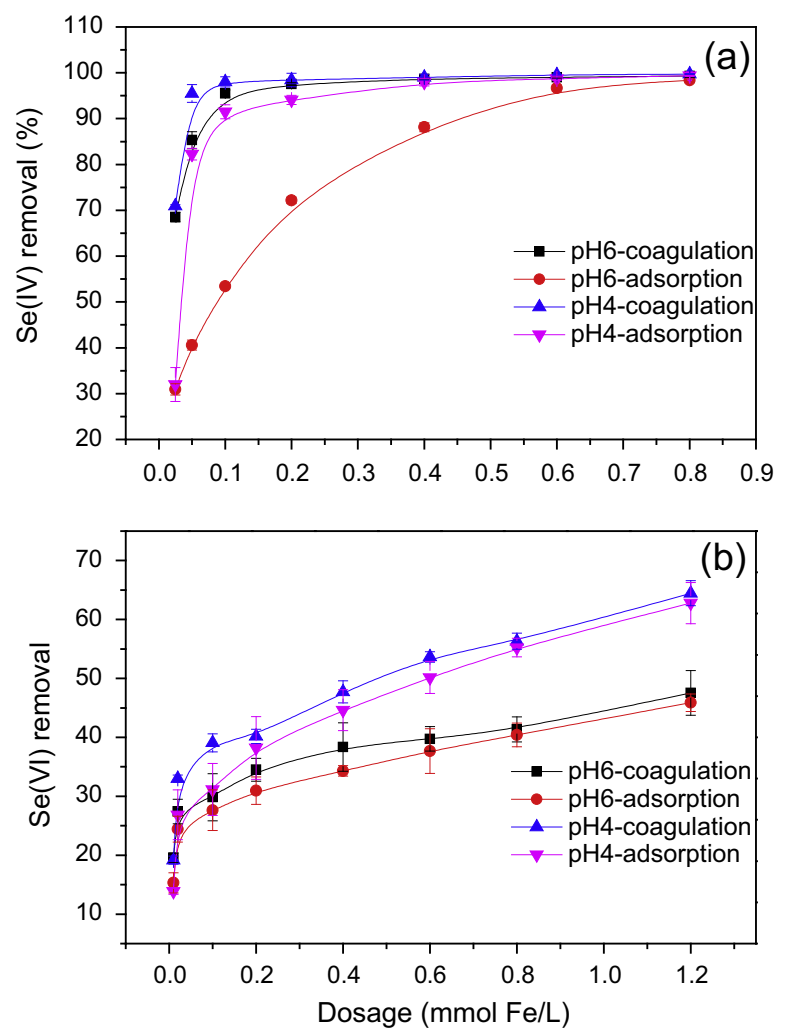

Fig. 6. Se removal by FC and adsorption on preformed FC flocs. 
of anionic contaminants. Since fewer hydroxide flocs occur at low coagulant dosages, coprecipitation of Se(IV) into growing hydroxide flocs via inclusion or occlusion seems to be difficult to occur as the predominant mechanism. Therefore, a precipitation mechanism, with formation of insoluble $\mathrm{Al}_{2}\left(\mathrm{SeO}_{3}\right)_{3}$ or $\mathrm{Fe}_{2}\left(\mathrm{SeO}_{3}\right)_{3}$ [40], may play an important role in $\mathrm{Se}(\mathrm{IV})$ coagulation at low dosage.

Fig. 5a shows that Se(IV) removal by AC coagulation was higher than that by $\mathrm{PACl}$ coagulation, but $\mathrm{Se}(\mathrm{IV})$ removal by $\mathrm{AC}$ floc adsorption was lower than that by $\mathrm{PACl}$ floc adsorption. Fig. 5b shows that $\mathrm{Se}(\mathrm{VI})$ removal by both coagulation and adsorption on $\mathrm{PACl}$ was higher than those for AC. These results indicated that $\mathrm{PACl}$ flocs had stronger adsorption affinity for Se than AC flocs did. As shown in Figs. $3 \mathrm{~b}$ and $4 \mathrm{~b}$, the surface potential of PACl flocs at pH 6 was higher than that of AC flocs, which might lead to a greater attractive force between $\mathrm{PACl}$ flocs and Se ions. Adsorption onto formed hydroxide flocs was more active during $\mathrm{PACl}$ coagulation to remove Se. Precipitation was relatively more active during AC coagulation to remove Se. The predominant $\mathrm{Al}$ species of $\mathrm{AC}$ is $\mathrm{Al}$ monomer, while $\mathrm{Al}_{13}$ polymer is the dominant $\mathrm{Al}$ species in $\mathrm{PACl}$. The monomer may more easily complex with Se ions compared with $\mathrm{Al}_{13}$ polymer since the binding sites of $\mathrm{Al}$ in $\mathrm{Al}_{13}$ polymer are occupied by hydroxyl.

During adsorption onto preformed flocs, Se removal depended on the coagulant dose and consequently on the number of active sites on the hydroxide flocs' surfaces. As mentioned above, FC could produce more flocs due to the lower solubility of hydrous $\mathrm{Fe}$ oxides. Moreover, it is believed that the structure of $\mathrm{Fe}$ hydroxide flocs is more open and loose than that of Al hydroxide flocs, ensuring a large available surface area for adsorption [41]. Consequently, Fe hydroxide flocs had a greater affinity toward $\mathrm{Se}(\mathrm{IV})$ and $\mathrm{Se}(\mathrm{VI})$ than $\mathrm{Al}$ hydroxide flocs, thereby bringing about higher Se removal efficiency for FC coagulation. Figs. 3 and 4 show that the zeta potential of FC hydroxide flocs at $\mathrm{pH} 4$ was higher than that at $\mathrm{pH} \mathrm{6}$, thus Fe hydroxide flocs generated at $\mathrm{pH} 4$ may have a greater affinity toward $\mathrm{Se}(\mathrm{IV})$ and $\mathrm{Se}(\mathrm{VI})$ than those at $\mathrm{pH}$ 6 . This may contribute to the higher Se removal at $\mathrm{pH} 4$ during the FC coagulation process.

\subsection{Effect of co-existing anions on Se removal}

At a fixed $\mathrm{pH}$ of 6 , the effects of four common oxyanions at three concentration levels $(0.1,1.0$ and $10 \mathrm{mM})$ on $\mathrm{Se}(\mathrm{IV})$ removal are illustrated in Fig. 7. In the presence of $\mathrm{SO}_{4}^{2-}, \mathrm{CO}_{3}^{2-}, \mathrm{SiO}_{3}^{2-}$ and $\mathrm{PO}_{4}^{3-}$, the $\mathrm{Se}(\mathrm{IV})$ removal decreased to varying degrees. The effect of co-existing anions on Se(IV) removal by AC was more pronounced than that by $\mathrm{FC}$. $\mathrm{PO}_{4}^{3-}$ caused the greatest percentage decrease in Se(IV) removal among the anions at each concentration level. Although sulfur and Se are located in the same main group of the periodic table, the influence of $\mathrm{SO}_{4}^{2-}$ on Se removal was lowest among the four oxyanions. The negative influence on $\mathrm{Se}(\mathrm{IV})$ removal among the four oxyanions followed the order: $\mathrm{PO}_{4}^{3-}>\mathrm{SiO}_{3}^{2-}>\mathrm{CO}_{3}^{2-}>\mathrm{SO}_{4}^{2-}$, which is similar to the result of adsorptive $\mathrm{Se}(\mathrm{IV})$ removal using iron-coated GAC adsorbents [17]. Since adsorption onto hydroxide flocs is the main coagulation mechanism for Se(IV) removal by Al- and Fe-based coagulants, the results can be explained by the triple layer model, which is widely used to describe solid-liquid interface adsorption [42]. $\mathrm{PO}_{4}^{3-}$ can bind strongly with the surface sites of metal hydroxides, forming inner-sphere (o-plane) surface complexes that are barely affected by ionic strength. In contrast, sulfate is weakly bound to the surface sites. The complex formation usually takes place on outer-sphere (o-plane) and is significantly affected by ionic strength. This can explain why $\mathrm{PO}_{4}^{3-}$ has a relatively larger negative effect than $\mathrm{SO}_{4}^{2-}$. For $\mathrm{SiO}_{3}^{2-}$ and $\mathrm{CO}_{3}^{2-}$, the competition between the two anions and Se(IV) may involve another reaction mechanism, surface accumulation/precipitation [16,43].

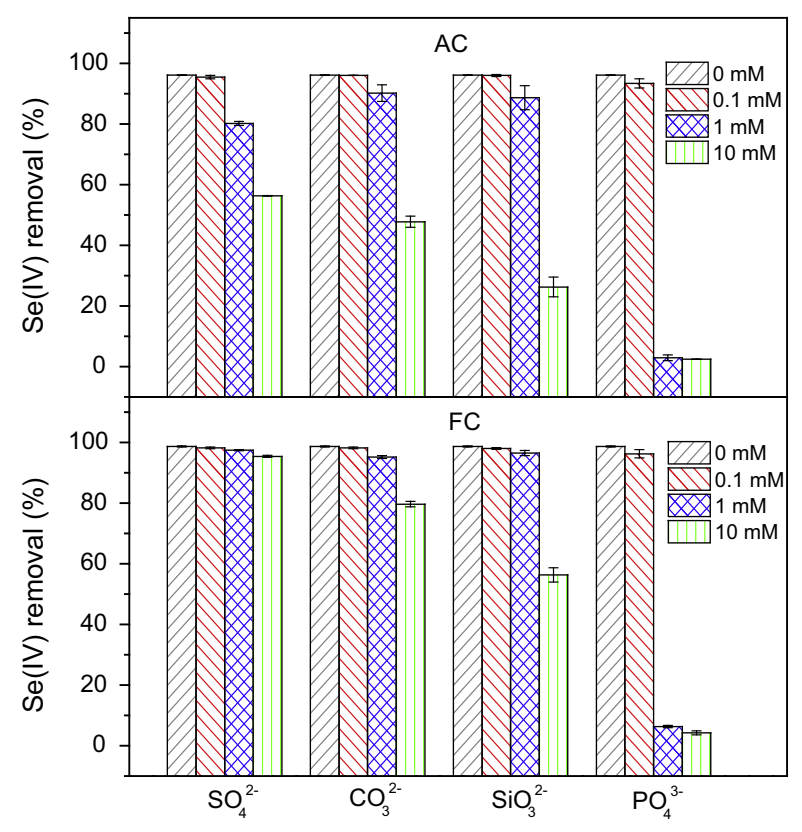

Fig. 7. Effect of co-existing anions on $\mathrm{Se}(\mathrm{VI})$ removal by coagulation. The dosages of $\mathrm{Al}$ based coagulants and FC were constant at $0.8 \mathrm{mmol} \mathrm{Al} / \mathrm{L}$ and $0.1 \mathrm{mmol} \mathrm{Fe} / \mathrm{L}$, respectively. Water $\mathrm{pH}$ was constant at 6 .

In addition, the competing anions may have accumulated or precipitated on the metal hydroxide surface, which in turn reduced the surface potential of the hydroxide flocs. The resulting electrostatic repulsion between $\mathrm{Se}(\mathrm{IV})$ and the hydroxide surface sites increased, which reduced Se(IV) adsorption and thus the Se(IV) removal by coagulation decreased. As mentioned above, compared with Al-based coagulants, the hydroxide flocs of FC have more surface adsorption sites for Se(IV) removal. Consequently, the negative interference of co-existing anions on Se(IV) removal by FC was less than that by AC.

\section{Conclusions}

The principal conclusions of this study are as follows:

1. The Fe-based coagulant was much more efficient than the Albased coagulants. Compared with $\mathrm{Se}(\mathrm{VI}), \mathrm{Se}(\mathrm{IV})$ could be more easily removed by coagulation. With an FC dosage of more than $0.4 \mathrm{mM} \mathrm{Fe} / \mathrm{L}, \mathrm{Se}(\mathrm{IV})$ removal efficiency of more than $98 \%$ could be achieved when the initial Se(IV) concentration was $250 \mu \mathrm{g} /$ L. Our results indicated that coagulation with iron salt is an effective treatment technique for Se(IV) removal.

2. Adsorption onto hydroxide flocs was the most active coagulation mechanism for Se removal and precipitation also played specific roles at low dosage, especially for Se(IV) removal and with the Fe coagulant. The surface character of hydroxide flocs, especially the zeta potential and active adsorption sites, determined the coagulation performance in Se removal. For Al-based coagulants, Se removal efficiency was positively correlated with the content of $\mathrm{Al}_{13}$ species during the coagulation process.

3. High coagulant dosage and weakly acidic $\mathrm{pH}$ conditions favored Se removal. AC performed better than PACl for Se removal under weakly acidic $\mathrm{pH}$ conditions. Compared to the performance of Al-based coagulants, Se removal by FC was relatively independent on water $\mathrm{pH}$ and insensitive to the presence of oxyanions. The negative influence on $\mathrm{Se}(\mathrm{IV})$ removal among the four oxyanions tested followed the order: $\mathrm{PO}_{4}^{3-}>\mathrm{SiO}_{3}^{2-}>\mathrm{CO}_{3}^{2-}>\mathrm{SO}_{4}^{2-}$. 
Pre-reduction of $\mathrm{Se}(\mathrm{VI})$ to $\mathrm{Se}(\mathrm{IV})$ seems to be necessary to achieve effective Se removal. In addition, some coagulant aids, chitosan for example, may have the potential to enhance $\mathrm{Se}(\mathrm{VI})$ removal by coagulation. Whether the pre-reduction process or the coagulant aids are used, their efficiency in enhancing $\mathrm{Se}(\mathrm{VI})$ removal by coagulation needs to be evaluated.

\section{Acknowledgments}

The authors are grateful for financial support from the National Natural Science Foundation of China (Nos. 51378490 and 51225805) and the key project of the National "863" High-tech R\&D Program of China (2012AA062604).

\section{References}

[1] S. Sharma, R. Singh, Selenium in soil, plant, and animal systems, Crit. Rev. Environ. Control 13 (1984) 23-50.

[2] H.J.M. Bowen, Trace Elements in Biochemistry, Academic Press, San Diego, 1966.

[3] H.M. Ohlendorf, Selenium in Agriculture and the Environment, Soil Science Society of America, Madison, WI, 1989. p. 133.

[4] L.H.E. Winkel, C.A. Johnson, M. Lenz, T. Grundl, O.X. Leupin, M. Amini, L. Charlet, Environmental selenium research: from microscopic processes to global understanding, Environ. Sci. Technol. 46 (2012) 571-579.

[5] S.S. Huang, M. Hua, J.S. Feng, X.Y. Zhong, Y. Jin, B.W. Zhu, H. Lu, Assessment of selenium pollution in agricultural soils in the Xuzhou District, Northwest Jiangsu, China, J. Environ. Sci.-China 21 (2009) 481-487.

[6] M. Bajaj, E. Eiche, T. Neumann, J. Winter, C. Gallert, Hazardous concentrations of selenium in soil and groundwater in North-West India, J. Hazard. Mater. 189 (2011) 640-646.

[7] Y. Tamari, Methods of analysis for the determination of selenium in biological, geological, and water samples, Environ. Chem. Selenium 64 (1998) 27-46.

[8] M.G. Cobo Fernadez, M.A. Palacios, C. Camara, Flow-injection and continuousflow systems for the determination of $\mathrm{Se}(\mathrm{IV})$ and $\mathrm{Se}(\mathrm{VI})$ by hydride generation atomic absorption spectrometry with on-line prereduction of $\mathrm{Se}(\mathrm{VI})$ to $\mathrm{Se}(\mathrm{IV})$, Anal. Chem. Acta 283 (1993) 386-392.

[9] T. Nishimura, H. Hashimoto, M. Nakayama, Removal of selenium(VI) from aqueous solution with polyamine-type weakly basic ion exchange resin, Sep. Sci. Technol. 42 (2007) 3155-3167.

[10] B.J. Marinas, R.E. Selleck, Reverse-osmosis treatment of multicomponent electrolyte-solutions, J. Membr. Sci. 72 (1992) 211-229.

[11] K. Mondal, G. Jegadeesan, S.B. Lalvani, Removal of selenate by Fe and NiFe nanosized particles, Ind. Eng. Chem. Res. 43 (2004) 4922-4934.

[12] N. Yee, J. Ma, A. Dalia, T. Boonfueng, D.Y. Kobayashi, Se(VI) reduction and the precipitation of $\mathrm{Se}(0)$ by the facultative bacterium Enterobacter cloacae SLD1a-1 are regulated by FNR, Appl. Environ. Microbiol. 73 (2007) 1914-1920.

[13] N. Geoffroy, G.P. Demopoulos, The elimination of selenium(IV) from aqueous solution by precipitation with sodium sulfide, J. Hazard. Mater. 185 (2011) $148-154$.

[14] V. Mavrov, S. Stamenov, E. Todorova, H. Chmiel, T. Erwe, New hybrid electrocoagulation membrane process for removing selenium from industrial wastewater, Desalination 201 (2006) 290-296.

[15] W.H. Kuan, S.L. Lo, M.K. Wang, C.F. Lin, Removal of Se(IV) and Se(VI) from water by aluminum-oxide-coated sand, Water Res. 32 (1998) 915-923.

[16] D. Peak, D.L. Sparks, Mechanisms of selenate adsorption on iron oxides and hydroxides, Environ. Sci. Technol. 36 (2002) 1460-1466.

[17] N. Zhang, L.S. Lin, D.C. Gang, Adsorptive selenite removal from water using iron-coated GAC adsorbents, Water Res. 42 (2008) 3809-3816.

[18] J.A. Ippolito, K.G. Scheckel, K.A. Barbarick, Selenium adsorption to aluminumbased water treatment residuals, J. Colloid Interface Sci. 338 (2009) 48-55.
[19] L. Zhang, N. Liu, L. Yang, Q. Lin, Sorption behavior of nano- $\mathrm{TiO}_{2}$ for the removal of selenium ions from aqueous solution, J. Hazard. Mater. 170 (2009) 1197 1203.

[20] R.R. Sheha, E.A. El-Shazly, Kinetics and equilibrium modeling of Se(IV) removal from aqueous solutions using metal oxides, Chem. Eng. J. 160 (2010) 63-71.

[21] N. Bleiman, Y.G. Mishael, Selenium removal from drinking water by adsorption to chitosan-clay composites and oxides: batch and columns tests, J. Hazard Mater. 183 (2010) 590-595.

[22] M.O.M. Sharrad, H. Liu, M. Fan, Evaluation of FeOOH performance on selenium reduction, Sep. Purif. Technol. 84 (2012) 29-34.

[23] J.S. Yamani, A.W. Lounsbury, J.B. Zimmerman, Adsorption of selenite and selenate by nanocrystalline aluminum oxide, neat and impregnated in chitosan beads, Water Res. 50 (2014) 373-381.

[24] N. Jordan, A. Ritter, H. Foerstendorf, A.C. Scheinost, S. Weiss, K. Heim, J Grenzer, A. Muecklich, H. Reuther, Adsorption mechanism of selenium(VI) onto maghemite, Geochim. Cosmochim. Acta 103 (2013) 63-75.

[25] C.Z. Hu, H.J. Liu, J.H. Qu, D.S. Wang, J. Ru, Coagulation behavior of aluminum salts in eutrophic water: significance of $\mathrm{Al}_{13}$ species and $\mathrm{pH}$ control, Environ. Sci. Technol. 40 (2006) 325-331.

[26] J.-L. Lin, C.-J.M. Chin, C. Huang, J.R. Pan, D. Wang, Coagulation behavior of $\mathrm{Al}_{13}$ aggregates, Water Res. 42 (2008) 4281-4290.

[27] J.Y. Shin, R.F. Spinette, C.R. O'Melia, Stoichiometry of coagulation revisited Environ. Sci. Technol. 42 (2008) 2582-2589.

[28] J.M. Duan, J. Gregory, Coagulation by hydrolysing metal salts, Adv. Colloid Interface Sci. 100 (2003) 475-502.

[29] G.J. Lu, J.H. Qu, H.X. Tang, The electrochemical production of highly effective polyaluminum chloride, Water Res. 33 (1999) 807-813.

[30] J.W. Akitt, A. Farthing, ${ }^{27}$ Aluminum nuclear magnetic resonance studies of the hydrolysis of aluminum (III). Part 5. Slow hydrolysis using aluminum metal, J. Chem. Soc. Dalton Trans. (1981) 1624-1628.

[31] State Standard of the People's Republic of China, Standard Examination Methods for Drinking Water - Metal Parameters, GB/T 5750.6-2006.

[32] H. Zhao, H. Liu, C. Hu, J. Qu, Effect of aluminum speciation and structure characterization on preferential removal of disinfection byproduct precursors by aluminum hydroxide coagulation, Environ. Sci. Technol. 43 (2009) $5067-$ 5072.

[33] J.G. Hering, P.Y. Chen, J.A. Wilkie, M. Elimelech, S. Liang, Arsenic removal by ferric chloride, J. Am. Water Works Assoc. 88 (1996) 155-167.

[34] H. Zhao, J. Peng, S. Lin, Y. Zhang, Covalently bound organic silicate aluminum hybrid coagulants: preparation, characterization, and coagulation behavior, Environ. Sci. Technol. 43 (2009) 2041-2046.

[35] M.I. Aguilar, J. Saez, M. Llorens, A. Soler, J.F. Ortuno, Nutrient removal and sludge production in the coagulation-flocculation process, Water Res. 36 (2002) 2910-2919.

[36] X. Guo, Z. Wu, M. He, Removal of antimony(V) and antimony(III) from drinking water by coagulation-flocculation-sedimentation (CFS), Water Res. 43 (2009) 4327-4335.

[37] V. Pallier, G. Feuillade-Cathalifaud, B. Serpaud, J.-C. Bollinger, Effect of organic matter on arsenic removal during coagulation/flocculation treatment, J. Colloid Interface Sci. 342 (2010) 26-32.

[38] D.A. Georgantas, H.P. Grigoropoulou, Orthophosphate and metaphosphate ion removal from aqueous solution using alum and aluminum hydroxide, J. Colloid Interface Sci. 315 (2007) 70-79.

[39] C. Hu, H. Liu, G. Chen, J. Qu, Effect of aluminum speciation on arsenic removal during coagulation process, Sep. Purif. Technol. 86 (2012) 35-40.

[40] F. Seby, M. Potin-Gautier, E. Giffaut, G. Borge, O.F.X. Donard, A critical review of thermodynamic data for selenium species at $25^{\circ} \mathrm{C}$, Chem Geol. 171 (2001) 173-194.

[41] M. Kang, T. Kamei, Y. Magara, Comparing polyaluminum chloride and ferric chloride for antimony removal, Water Res. 37 (2003) 4171-4179.

[42] W. Stumm, J.J. Morgan, Aquatic Chemistry, John Wiley and Sons, New York, 1995.

[43] K.H. Goh, T.T. Lim, Geochemistry of inorganic arsenic and selenium in a tropical soil: effect of reaction time, $\mathrm{pH}$, and competitive anions on arsenic and selenium adsorption, Chemosphere 55 (2004) 849-859. 